\section{Burnout académico odontológico durante la pandemia por COVID -19}

\section{Academic dental burnout during the COVID-19 pandemic}

\section{Sr. Editor.}

Desde el pasado 14 de marzo del 2020, el Perú enfrenta una de las mayores pandemias en la historia de la humanidad; en respuesta a ello, el estado peruano se declaró en Emergencia Sanitaria e inmovilización social obligatoria. Además, en el sector educación, el Ministerio de Educación (MINEDU) brindó un conjunto de directrices para implementar la educación a distancia, optando por utilizar nuevas herramientas tecnológicas, que logren igualar las exigencias académicas presenciales.

El burnout académico abarca un conjunto de signos y síntomas desarrollados por el estrés prolongado que generan las actividades, relaciones interpersonales y el contexto académico en estudiantes universitarios. Son aquellos, quienes manifiestan ciertas actitudes como el desinterés hacia los estudios, compañeros o pacientes; un sentimiento de incompetencia académica; una sensación de encontrarse exhausto y no poder con las tareas como estudiante. En consecuencia, dicho síndrome puede afectar seriamente el proceso de aprendizaje. Para su evaluación científica, es utilizado el Maslach Burnout Inventory- Student Survey (MBI-SS) que mide sus tres dimensiones: agotamiento (cansancio emocional), cinismo (pérdida de interés) e ineficacia (inutilidad académica) ${ }^{1,2}$.

Un estudio de revisión sistemática basado en 12 artículos publicados entre el 2010 y 2015, realizado en estudiantes de Ciencias de la Salud, Ciencias Sociales, Ciencias de la Comunicación y Ciencias de la Educación y Humanidades demostró que, la prevalencia de síndrome de burnout universitario varía entre el $8 \%$ y $56,9 \%$ de acuerdo a la población estudiada ${ }^{3}$. Así mismo, en base a nuestra experiencia como estudiantes universitarios, hemos manifestado un cierto grado de ansiedad, depresión y estrés a causa de la incertidumbre generada por la pandemia; lo cual, afecta nuestro desarrollo académico y salud mental. Sumado

\section{Carta al Editor}

\author{
Joffer Miguel Alavedra-Martínez ${ }^{1,2, a}$, Wendy Jackelin \\ Cárdenas-Luján ${ }^{1,2, a}$ \\ ${ }^{1}$ Universidad Nacional San Luis Gonzaga, Facultad de \\ Odontología, Ica, Perú. \\ ${ }^{2}$ Semillero Universitario de Investigación de la Facultad \\ de Odontología (SUNIFO), Ica, Perú. \\ a Estudiante de Odontología.
}

\section{Correspondencia:}

Joffer Miguel Alavedra-Martinez: joffer_miguel_15@ hotmail.com

Av. Francisco Bolognesi S/N El Ingenio, Nasca. Perú ORCID: 0000-0002-6764-042X

\section{Coautor:}

Wendy Jackeline Cárdenas-Luján: menyi04@hotmail.com ORCID: 0000-0003-4050-7765

Conflicto de intereses: ninguno.

Fuente de financiamiento: autofinanciado.

Recibido: 22/03/21

Aprobado: 22/04/21

Publicado: 01/07/21

(c) Los autores. Este artículo es publicado por la revista Odontología Sanmarquina de la Facultad de Odontología, Universidad Nacional Mayor de San Marcos. Este es un artículo de acceso abierto, distribuido bajo los términos de la licencia Creative Commons Atribución 4.0 Internacional (CC BY 4.0) [https://creativecommons.org/ licenses/by/4.0/deed.es] que permite el uso, distribución y reproducción en cualquier medio, siempre que la obra original sea debidamente citada de su fuente original. 
a aquello, existe la preocupación por el desarrollo de prácticas preclínicas y clínicas, perfeccionamiento de habilidades propias de la carrera; más aún, con factores externos como la sobrecarga emocional por la pérdida de familiares afectados por el virus, la responsabilidad económica familiar e incluso por dificultades en el acceso a una conexión de internet estable, para el desarrollo de clases y prácticas virtuales.

En un estudio realizado en el 2016 a estudiantes de Ciencias de la Salud e Ingeniería, indicaron un nivel bajo y medio de agotamiento emocional y cinismo. Siendo los estudiantes de Odontología y Medicina quienes presentaron mayor agotamiento emocional, físico y mental que los otros ${ }^{2}$. Así mismo, en un estudio realizado en el 2017, se encontró que el 62,50\% de los estudiantes presentó un alto nivel de agotamiento emocional, considerando además que los estudiantes de último año de la carrera enfrentan una carga académica y una exigencia mucho mayor, por lo que disminuirá eventualmente su capacidad para una mejor atención a los pacientes y la solución de problemas bucales de mayor complejidad ${ }^{4}$. De igual importancia, un estudio publicado en el 2019, encontró agotamiento emocional de moderado a alto nivel $^{5}$. Estos hallazgos demuestran un problema latente en la población estudiantil, toda vez, que se ven influenciadas negativamente por las características propias de la pandemia.

Es así, que la universidad tiene la responsabilidad en cuanto al bienestar de los estudiantes. Cobo, et al. ${ }^{6}$ sostienen que la universidad es un microsistema social que tiene la obligación y la capacidad de responder ante la sociedad por sus acciones, omisiones e impactos. Al hacerse responsable de la salud mental de sus estudiantes, se hace cargo directamente de sus impactos organizacionales; genera una comunidad educativa socialmente ejemplar (impacto gestión), la manera de interpretar el mundo y de comportarse en él (impacto educativo). Además, influye en la definición y selección de los problemas de la agenda científica, generando pertenencia ante la contingencia social y sus destinatarios (impacto cognitivo).

Por lo tanto, siendo el burnout académico una problemática a largo plazo que produce menoscabo al desarrollo profesional, debido a la alta demanda académica y la coyuntura que atravesamos, es necesario que las instituciones universitarias, muestren mayor responsabilidad social hacia la comunidad estudiantil en los tiempos actuales de crisis; no solo brindando facilidades económicas, sino incorporando una educación integral, área de psicología, centros o actividades de recreación, así como, fomentar la investigación científica no solo en temas de carrera propia, sino de cuestiones que afecten la salud mental e integral de los estudiantes universitarios de odontología, para que de este modo se logre mitigar el impacto psicológico de la pandemia por COVID-19.

\section{Referencias bibliográficas}

1. Caballero CC, Breso E, González Gutiérrez O. Burnout en estudiantes universitarios. Psicología desde el Caribe [Internet]. 2015 [Citado el 21 de febrero de 2021];32(3):428. Disponible en: http://www.scielo.org. co/pdf/psdc/v32n3/v32n3a07.pdf

2. Ferrel Ortega FR, Ferrel Ballestas LF, Cantillo Aguirre AA, Jaramillo Campo JJ, Jiménez Suárez SM. Variables académicas y sociodemográficas relacionadas con el Síndrome de Burnout, en estudiantes de Ingenierías y Ciencias de la Salud de una universidad estatal de Colombia. Psicogente [Internet]. 2017 [Citado el 29 de marzo de 2021]; 20(38):336-352. Disponible en:http:// www.scielo.org.co/pdf/psico/v20n38/0124-0137-psico-20-38-00336.pdf

3. Loayza Castro JA, Correa López LE, Cabello Vela CS, Huamán García MO, Cedillo Ramírez L, Vela Ruiz JM, et al. Síndrome de Burnout en estudiantes universitarios: Tendencias Actuales. Rev. Fac. Med. Hum. [Internet] 2016 [Citado el 21 de febrero de 2021];16(1):31-36. Disponible en:https://www.researchgate.net/publication/318074340_sindrome_de_burnout_en_estudiantes_universitarios_tendencias_actuales

4. Gil Álvarez JA, Cruz Cruz D. Academic burnout and engagement in fifth-year Stomatology students. EDUMECENTRO [Internet]. 2018 Dic [citado el 16 de marzo de 2021];10(4):37-53. Disponible en: http://scielo.sld.cu/scielo.php?script=sci_arttext\&pi$\mathrm{d}=$ S2077-28742018000400003\&lng=es

5. Castro Rodríguez Y, Valenzuela-Torres O, Hinojosa-Añorga M, Piscoche-Rodríguez C. Agotamiento emocional en estudiantes de Odontología de la Universidad Nacional Mayor de San Marcos. Rev haban cienc méd [Internet]. 2019 [citado 16 de marzo de 2021];18(1):[aprox.13p.]. Disponible en:http://www. revhabanera.sld.cu/index.php/rhab/article/view/2427

6. Cobo Rendón R, Vega Valenzuela A, García Álvarez D, Consideraciones institucionales sobre la Salud Mental en estudiantes universitarios durante la pandemia de $\mathrm{CO}-$ VID-19. CienciAmérica [Internet] 2020 [Citado el 23 de febrero de 2021], Vol. 9(2) Disponible en: http:// cienciamerica.uti.edu.ec/openjournal/index.php/uti/article/view/322 